\title{
Erratum to: The Regularized Mesh Scheme to Solve Quasilinear Parabolic Equation with Time-Fractional Derivative
}

\author{
A. V. Lapin ${ }^{1 *}$ and E. Laitinen ${ }^{2 * *}$ \\ (Submitted by A. M. Elizarov) \\ ${ }^{1}$ Department of Higher Mathematics, Mechanics, and Mathematical Modelling, \\ Institute of Personalized Medicine, Sechenov University, Moscow, 119435 Russia \\ ${ }^{2}$ Faculty of Science, Research Unit of Mathematical Sciences, University of Oulu, Oulu, Finland \\ Received August 13, 2021; revised August 13, 2021; accepted August 13, 2021
}

DOI: $10.1134 / \mathrm{S} 1995080221100231$

The article "The Regularized Mesh Scheme to Solve Quasilinear Parabolic Equation with TimeFractional Derivative", written by A. V. Lapin and E. Laitinen, was originally published electronically in Springer-Link on 9 August 2021 without Open Access. After publication in volume 42, issue 7, pages 1706-1714 the authors decided to make the article an Open Access publication. Therefore, the copyright of the article has been changed to (C)The Author(s), 2021 and the article is forthwith distributed under the terms of a Creative Commons Attribution 4.0 International License (http://creativecommons.org/licenses/by/4.0/, CC BY), which permits use, duplication, adaptation, distribution and reproduction of a work in any medium or format, as long as you cite the original author(s) and publication source, provide a link to the Creative Commons license, and indicate if changes were made.

The original article can be found online at https://doi.org/10.1134/S1995080221070155

\footnotetext{
${ }^{*}$ E-mail:avlapine@mail.ru

**-mail:erkki.laitinen@oulu.fi
} 